\title{
Age at repair and left ventricular mass in patients after repair of aortic coarctation
}

\author{
Joris W. J. Vriend, MD, a Peter M. Engelfriet, MD, ${ }^{\text {a }}$ Eric de Groot, MD, PhD, ${ }^{\text {b }}$ Bart M. Elsen, MSc, ${ }^{\text {b }}$
}

John J. P. Kastelein, MD, PhD, and Barbara J. M. Mulder, MD, PhD, ${ }^{\text {a }}$ Amsterdam, The Netherlands

$\mathrm{M}$ yocardial and vascular abnormalities often persist in patients despite early repair of aortic coarctation. Several studies on postcoarctectomy patients reported no significant associations between age at repair and left ventricular mass. ${ }^{1,2}$ However, these studies used echocardiographic 2-dimensional guided M-mode tracings for analysis of left ventricular mass, whereas assessment of left ventricular mass determined by cardiac magnetic resonance (CMR) imaging has shown a far better correlation with postmortem ventricular weights. ${ }^{3}$ The aim of this study was to identify independent predictors of left ventricular mass assessed by CMR imaging in adult postcoarctectomy patients.

\section{Methods and Results}

In 2001, 111 consecutive adult postcoarctectomy patients (73 male patients) underwent ambulatory blood pressure monitoring in the right arm, echocardiography, CMR imaging of the aorta, and B-mode ultrasound imaging of the carotid arteries. Hypertension was defined as a mean daytime blood pressure of $135 / 85 \mathrm{~mm} \mathrm{Hg}$ or greater. Residual aortic valve gradients were assessed. The proximal descending aorta/diaphragmatic aorta ratio was determined by magnetic resonance angiograms. CMR imaging acquisition and analysis of left ventricular mass involved a standardized protocol. B-mode ultrasound images of both common carotid arteries were acquired, and mean intimalmedial thickness (IMT) was assessed. Multivariable stepwise regression analysis was used to identify independent predictors of left ventricular mass. All variables significantly associated with left ventricular mass in the univariate analysis $(P<.10)$ were included in the multivariable regression model. Variables included were body surface area, age, age at repair, sex, antihypertensive medication, mean daytime systolic and diastolic blood pressures, common carotid IMT, arm-leg blood pressure

\footnotetext{
From the Departments of Cardiology ${ }^{\mathrm{a}}$ and Vascular Medicine, ${ }^{\mathrm{b}}$ Academic Medical Center, Amsterdam, The Netherlands.

Received for publication March 7, 2005; accepted for publication March 22, 2005 .

Address for reprints: Joris W. J. Vriend, MD, Department of Cardiology, Room B2-216, Academic Medical Center, 1100 DE Amsterdam, The Netherlands (E-mail: j.w.vriend@amc.uva.nl).

J Thorac Cardiovasc Surg 2005;130:896-7

$0022-5223 / \$ 30.00$

Copyright (C) 2005 by The American Association for Thoracic Surgery doi:10.1016/j.jtcvs.2005.03.026
}

gradient, descending aorta/diaphragmatic aorta ratio, and an aortic valve gradient of greater than $20 \mathrm{~mm} \mathrm{Hg}$ or aortic valve prosthesis.

Mean age was 31.2 years (range, 17-74 years), and mean age at repair was 7.8 years (range, 0.01-46 years). Fourteen patients had undergone repair before the age of 1 year. Repair was performed by resection and end-to-end anastomosis in $82(74 \%)$ patients. Of the 111 patients, $64(58 \%)$ had hypertension at ambulatory blood pressure monitoring. Six patients had a peak aortic valve gradient of $20 \mathrm{~mm} \mathrm{Hg}$ or greater. In addition, another 5 patients had an aortic valve prosthesis. One patient refused CMR imaging. In 2 patients no adequate analysis of the MRI images could be performed. Sex $(P<.0001)$, body surface area $(P=.001)$, and common carotid artery IMT $(P=$ $.006)$ were strongly associated with left ventricular mass in multivariable stepwise regression analysis.

\section{Discussion}

Using CMR imaging, we found that left ventricular mass was not associated with age at repair but was strongly associated with common carotid IMT (Figure 1). Both left ventricular hypertrophy and increased IMT are independent cardiovascular risk factors and are considered target organ damage that might



Figure 1. Relation of left ventricular mass and common carotid intimal-medial thickness in 108 postcoarctectomy patients. The adjusted $R^{2}$ value of the model was 0.479 . $L V$ mass, Left ventricular mass; IMT, intimal-medial thickness. 
complicate hypertension. Our findings suggest that age at repair might not be as important in the development of left ventricular hypertrophy and vascular damage in postcoarctectomy patients as is often believed.

Our findings support the hypothesis that aortic coarctation forms part of an extensive developmental abnormality of the proximal systemic arterial system also involving the left ventricle and the carotid arteries. Nowadays, early correction is recommended to reduce the risk of future sustained hypertension, but its effect on the left ventricle and proximal arteries might be less important than previously thought.

\section{References}

1. Johnson MC, Gutierrez FR, Sekarski DR, Ong CM, Canter CE. Comparison of ventricular mass and function in early versus late repair of coarctation of the aorta. Am J Cardiol. 1994;73:698-701.

2. Vriend JW, van Montfrans GA, Romkes HH, Vliegen HW, Veen G, Tijssen JG, et al. Relation between exercise-induced hypertension and sustained hypertension in adult patients after successful repair of aortic coarctation. J Hypertens. 2004;22:501-9.

3. Bottini PB, Carr AA, Prisant LM, Flickinger FW, Allison JD, Gottdiener JS. Magnetic resonance imaging compared to echocardiography to assess left ventricular mass in the hypertensive patient. Am J Hypertens. 1995;8:221-8.

\title{
Partial left ventriculectomy for infantile ischemic cardiomyopathy caused by anomalous origin of the left coronary artery from the pulmonary artery
}

\begin{abstract}
Masaaki Yamagishi, MD, PhD, ${ }^{a}$ Keisuke Shuntoh, MD, ${ }^{a}$ Takeshi Shinkawa, MD, Takahiro Hisaoka, MD, ${ }^{a}$ Mitsugu Ogawa, MD, ${ }^{a}$ Keitarou Kohshi, MD, ${ }^{a}$ Hitoshi Yaku, MD, PhD, You Kajiyama, MD, ${ }^{\mathrm{b}}$ and Kenji Hamaoka, MD, PhD, Kyoto, Japan
\end{abstract}

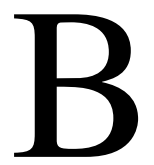
road ischemia of the left ventricle and subsequent severe ventricular failure are unavoidable in infants with anomalous origin of the left coronary artery from the pulmonary artery (ALCAPA). Here we report the first case of successful partial left ventriculectomy in a 3-month-old infant with severe ischemic cardiomyopathy caused by ALCAPA and vanishingly scarce collateral vessels.

\section{Clinical Summary}

A 3-month-old female infant weighing $5300 \mathrm{~g}$ with congestive heart failure was referred to our hospital. Abnormal Q waves were detected in leads I and aVL and precordial leads V4 through V6 on electrocardiography. Echocardiography demonstrated marked left ventricular (LV) dilatation with significant reduction in ventricular wall thickness (Figure 1, left). The LV end-diastolic diameter was $48 \mathrm{~mm}$. Wall motion showed marked diffuse deterioration. Shortening fraction was reduced to $7 \%$. Posterolateral wall thickness

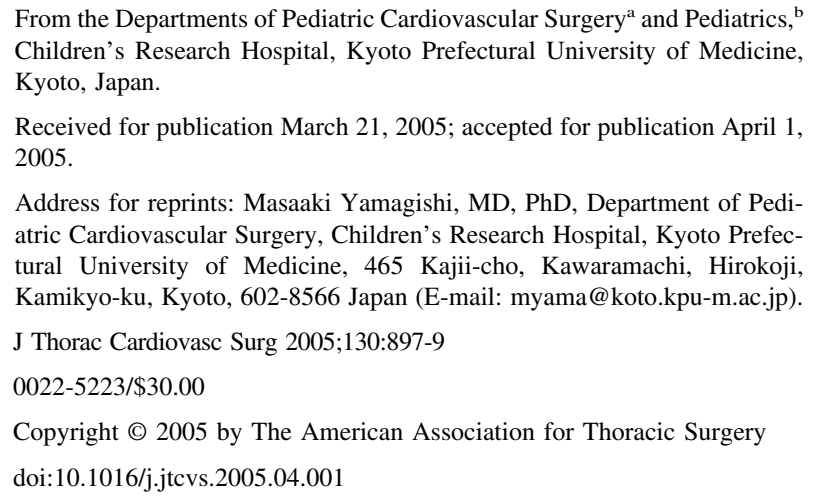
atric Cardiovascular Surgery, Children's Research Hospital, Kyoto Prefectural University of Medicine, 465 Kajii-cho, Kawaramachi, Hirokoji, Kamikyo-ku, Kyoto, 602-8566 Japan (E-mail: myama@koto.kpu-m.ac.jp)

J Thorac Cardiovasc Surg 2005;130:897-9

$0022-5223 / \$ 30.00$

Copyright $\odot 2005$ by The American Association for Thoracic Surgery doi:10.1016/j.jtcvs.2005.04.001

faded to $2 \mathrm{~mm}$. The papillary muscles and endocardium showed markedly increased echogenicity. Severe mitral regurgitation was also ob-

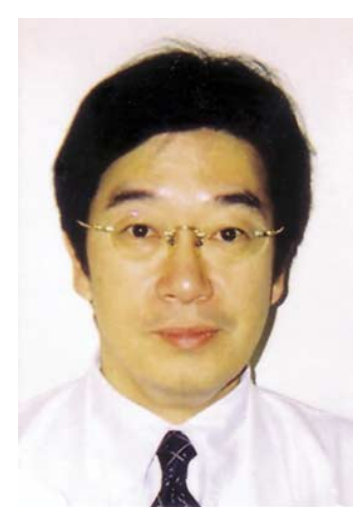

Dr Yamagishi served. The left coronary artery originated from the left posterior sinus of the pulmonary artery. ${ }^{201}$ Thallium myocardial scintigraphy demonstrated broad ischemia and the absence of myocardial viability at the posterolateral wall of the left ventricle.

The infant underwent reimplantation of the left coronary artery and partial left ventriculectomy. After institution of moderately hypothermic cardiopulmonary bypass and subsequent chemical cardiac arrest, the pulmonary artery was transected at the bifurcation. The pulmonary cuff, including the left coronary orifice, was harvested and implanted directly into the left lateral aortic wall. This was followed by mitral annuloplasty at the posterocommissural line.

The LV wall showed dark red discoloration and was markedly reduced in thickness. Island-shaped scar formations were also observed. The lateral LV wall measuring $25 \times 40 \mathrm{~mm}$ was resected in an elliptical shape along the left ascending coronary artery (Figure 2). Histologic examination showed significant transmural myocardial infarction. The ventriculotomy was closed longitudinally with reinforcing polytetrafluoroethylene felt strips. Coercive weaning from the cardiopulmonary bypass was not attempted because the patient had a high left atrial pressure of $23 \mathrm{~mm} \mathrm{Hg}$. The infant was placed on an extracorporeal circulatory support system and was weaned easily from this circulatory support system on the third postoperative day.

Postoperative echocardiography (Figure 1, right) showed marked improvement in LV function and a significant decrease in 